\title{
Research on the Different Ways of Thinking between Chinese and Western People and Barriers in Cross-cultural Communication
}

\author{
Jing Yang ${ }^{1}$ \\ ${ }^{1}$ Zhengzhou University of Industrial Technology, Henan, China
}

Keywords: The Ways Of Thinking; Cross-Cultural Communication; Culture Barriers.

\begin{abstract}
Thinking is a mental process revealing how people get to know the outside world. Thinking modes have the characteristic of stability, structurization and stylization. Therefore, the ways of thinking is the thinking structure which has certain popularity and stability, and it is formed in the process of human cognition. Cross-cultural communication is the communication among people in different culture backgrounds. Different cultures cause kinds of differences between China and the West, and among them the different ways of thinking is the most basic one. This paper mainly studies the problems that arise due to different ways of thinking between China and the West and provides some ways to handle with these problems so as to reduce or avoid culture barriers in cross-cultural communication between China and the West.
\end{abstract}

\section{Introduction}

Different ways of thinking are essential performances of the cultural differences. People who live in different regions have different cultural characteristics and different traditional thinking ways. People living in the specific natural geographical environment will have specific historical backgrounds and cultural traditions, so they will have different ways of thinking. The ways of thinking include the characteristics of nationality, era, region and society. This article discusses the general characteristics of Chinese and western people and finds out the causes of impact on cross-cultural communication.

The ways of thinking stand for the core of culture, which are the main designer and undertaker in the human culture. In order to study the different thinking ways of Chinese and westerners and reveal the mysteries and significance of the thinking ways, it is important for people to understand and respect the differences of Chinese culture and western culture. Thus, people can improve cross-cultural communicative competence and communicate with others who come from different countries.

\section{Different Thinking Ways between Chinese and Western People}

Holistic Thinking and Individual Thinking. Chinese traditional culture emphasizes the unification of individual, group and society. Personal existence and development should be unified with the development of whole family and society. The holistic thinking requires individual benefits to submit to group benefits. When the two sides come into conflicts, the individual must restrain their wishes and requirements, and even sacrifice personal benefits and submit to the benefits of the family and social groups.

The family is the cell of society in China, while the individual is the cell of society in the West. Westerners stress the importance of individual, who regard the individual as the core of society. The westerners emphasize self-made success and struggle to promote social development through personal effort. The society will not develop without personal development. Western thinking ways emphasize too much on the individual and people pay less attention to the relationship and the interpersonal communication among family members.

Experienced Thinking and Logical Thinking. The formation of a national way of thinking has a close relation with historic conditions, geographical environment and cultural traditions, which forms different thinking ways of Chinese people and westerners. 
Chinese traditional thinking ways stay in the perceptual stage, which have not risen to the rational thinking. It pays much attention to practical experiences. With the help of visual experiences and presentative feeling, people grasp inherent essence and laws of cognitive object directly. Chinese people are complacent through summarizing the experiences and describing the phenomena, rather than pursuing deeper intuitive thinking of the natural things behind the phenomenon of philosophical speculation. For example, Chinese built Hong Bridge in the Song Dynasty. This kind of bridge has been very popular at that time, while it does not exist now, because the skills of bridge-building have disappeared. Ancient Chinese science and technology mostly focus on intuitive summary and the experiences, lacking of logical and critical thinking, so it is impossible to rebuild this construction.

Westerners prefer analytical and logical reasoning, so the western thinking ways pay attention to analysis and abstraction. Western philosophers are keen to make a complete analysis on the object and explore the essence of things through making all kinds of experiments, such as, removing the appearance of things and finding out their inner link after analyzing. Ancient Greek philosopher Aristotle created a formal logic, presenting the three basic laws of formal logic: always the same, the law of contradiction, excluded middle; studying the three elements of argumentation: concept, judgment, reasoning; putting forward two kinds of thinking: induction, deduction. Logic also makes the ways of western thinking more rational, analytical, empirical, accurate and systematic series of features.

Circular Thinking and Linear Thinking. Kaplan Robert has come up with the cultural thinking influence on the patterns of discourse. He thinks that westerners have linear thinking and Chinese people have circular thinking. Circular thinking leads to the spiral structure of Chinese people. So when Chinese people write an article, they use a repetitive, developmental and helical structure and try to avoid entering the theme directly.

Western people think that heaven and mankind separate from each other and things are independent. All of things are always changing. As for linear thinking, when people speak or write something, they tend to use a direct expression instead of indirect expression, because they do not like to use irrelevant information to conceal true points. English articles include four parts: lead-in, theme, support and conclusion.

\section{Causes of Thinking Differences between China and the West}

Different Traditional Philosophy. Western traditional philosophy is different from Chinese, which emphasizes science and truth. The ancient Greek philosophers are natural scientists too, who treat the essence of things as the ultimate goal of research. They focus on the basis of truth, assumption and experiment. They observe, think, analyze and argue, then eventually strive to capture the essence of things. Ancient Greek philosopher Aristotle considered seeking knowledge as an exploration of human natural philosophy, which originated from surprising at everything in nature. Bacon believed that knowledge is power. And people can use the knowledge to know nature, discover nature and conquer nature, which are the concepts of western thinking. With the development of nature and science, western philosophers made the analytic and logic thinking more perfect through experiments. But western philosophy starts from opposition. Westerners cared about reasoning judgment, which prompts the formations of the western thinking ways.

Chinese traditional philosophy emphasizes on moral and ethics, so science and truth are often neglected by Chinese people. Chinese traditional philosophy regard the world as a continuum in the composition of two opposite things, whose world is interdependent and inseparable. Ancient Chinese people advocated "harmony between the heaven and human" and emphasized on the dialectical and unitive relationship between human and nature. Chinese ancient poetry says "the bold string rattled like splatters of sudden rain, the fine strings seem like whispering", which is the analogical reasoning from natural phenomena to the social phenomena, from abstraction to concreteness.

Different Geographical Environment and Economic Forms between Chinese and Western. The formation of Chinese and western thinking ways is closely related with relationship between Chinese and western geographical environment and economic forms. 
Western culture originates from the openness of the Greek peninsula and adjacent coastal area. Because of the special marine geographic environment, western has early development of maritime trade, handicraft industrial business and seafaring. Facing the challenge of marine environment, ancient Greeks had a great interest in astronomy, weather, geometry, math and physic, so that western people put effort to explore the mysteries of nature that concerned on scientific theory and technology.

The birth place of China is located in the inland, which has good climate and suitable soil for farming. So China has entered into an agricultural society in early time. People who living in mainland of China was engaged in agricultural production. They were lack of communication and competition with other civilizations and relatively isolated from outside world. Besides, they are self-centered and consider China as the whole world. And they rely on agriculture and weather. Chinese people emphasize on interpersonal harmony, group interest and overlook the individual, so they are weak of competitive consciousness. Traditional farming economy of China makes people realize that human can not live without the gift of nature, so Chinese people prefer the personification of nature and the naturalization of humans.

Different Religions. In general, the westerners believe in God. They believe that God is absolute and eternal and God can control everything, that is to say, the world has a universal law. Early Buddhism in China, people express more words about Buddha, such as "We", "the Lord Buddha blesses you" and so on. While Chinese people believe that the world is functioning of itself and God can not control it. It is clear that the different viewpoints of Chinese and western religions have certain effects on the formation of Chinese and western ways of thinking.

Different Cultural Backgrounds. People express ideas and thoughts in different ways under the differences of cultural backgrounds. Confucianism is the core of traditional culture and Chinese people are modest and complication. So they always use euphemistic words to emphasize on politeness, such as maybe, probably and so on. However, westerners like logical expression with direct "yes" or "no" answer. When they communicate with others, they should avoid using fuzzy words, such as, maybe, probably, almost or ostentation language and so on. Different cultural backgrounds lead to the different expressions which reflected in different aspects. For example, the usage of greetings is common behavior in daily life. Chinese people will ask each other about age, marriage, salary naturally, especially the dialogue between the old and the young. The older are more likely to the following questions: are you married? How many children do you have? But westerners think these questions are individual privacy for them. Chinese people and westerners maybe unconsciously hurt each other's feeling in the cross-cultural conversation.

\section{Main Barriers in the Cross-cultural Communication by Different Thinking Ways}

Different position expressions. Western people prefer analytic thinking while Chinese prefer synthetic thinking. Chinese thinking ways always divide whole objective into many parts, while westerners are opposite. The different position expressions of two thinking ways are: westerners usually introduce themselves from small towns to big cites when they mention a place, while Chinese people are opposite. It can be seen in the address: 256, Louisiana Street, Houston, Texas, USA, which is from door number, street, city, province to nation. While Chinese address is described from nation, province, city, street to door number. This difference is also reflected in filling educational experiences in one's resume. Westerners write their learning experience from present degree to primary school, while Chinese people write it from primary school to present degree. These different expressions derive different ways of thinking.

Different Color Expressions. Different folks have different views on colors. Chinese people regard red as a propitious symbolism, who always decorate things with red when celebrating weddings. But westerners prefer to wear white wedding dresses when celebrating. Besides, due to different understanding of colors, there is no equivalent expression of color between Chinese and westerners. For example, Chinese people say: "Hong Cha", while foreigners say black tea rather than red tea. And the English expression of "black bread" is brown bread rather than black bread.

4.3 Different Cognitions of Subject and Object 
Chinese people like to combine the subject with the object, while westerners pay more attention to the objective things.

In western countries, sharp distinguish can be seen from subject and object. There are strict distinction between subject and object, such as: westerners often use passive sentences to express: "I was told", while Chinese people prefer: "some people told me". That is to say, Chinese people emphasize on "I", while westerners emphasize on "others".

Different Communicative Behaviors. Different thinking ways between Chinese and westerners cause different communicating behaviors and ways. "I" always be capital in English sentence. However, in order to prove that they are humble, Chinese people always call himself "Zai Xia", "Bi Ren", "Bu Cai" when they meet strangers. And westerners always make Chinese people feel uncomfortable in a straight way.

Westerners like challenging and showing themselves. For instance, they prefer adventure, novelty and stimulation. While Chinese people are always affected by the ideological of traditional Confucianism. Therefore, they prefer to obey conservative ideological moderation and pursue internal and external coordination.

\section{Measures of Dealing with Barriers in Cross-cultural Communication}

Sensitivity of Cultural Differences. In order to overcome the communication barriers, people should identify the superficial culture characteristics, recognize the subtle differences of culture and accept it by rational analysis. People feel the differences of culture from the perspective of the other side with the sensitivity.

Application of Western Mindset. Westerners and Chinese people have their own thinking ways. So people should try to avoid two phenomenons. When it is difficult to express ideas in English, Chinese people should consider what the native speakers will express if they meet with the same troubles. This way can improve the quality of cross-cultural communication.

By in-depth understanding the different cultures, expanding the inner space of the cultural psychology, putting themselves in a more profound cultural background, people can communicate with each other smoothly. The most important thing is to increase the level of understanding the western cultural knowledge and adapt to the communicative ways of western culture. In order to avoid the Chinglish, Chinese people also need get rid of their own thinking ways when they talk with people from other countries. Thus, Chinese people can communicate with foreigners smoothly in cross-cultural communication.

Creation of English Learning Environment. Chinese people should pay attention to accumulate idiomatic usage in English and record some different sentence patterns from western literature, films and television works. They should observe the language's social language environment consciously, then understand the different words and concepts. Moreover, they observe that decent languages should be used in proper occasion, combining the language with the social context. Therefore, by this way, people can speak idiomatic English and improve the ability of cross-cultural communication.

\section{Conclusion}

It can be seen that thinking ways have the characteristics of era and nation from above analysis. Thinking is a very important aspect of the cultural connotation. People have different thinking ways in different times. Even in the same era, the same ethnic people may have different thinking ways. With the development of cross-cultural exchange, mutual understanding are becoming deeper and deeper between westerners and Chinese. It is unwise to ignore different culture existence or adhere to the thinking ways of the nation to deal with all the problems in cultural exchange.

In communicating, Chinese should learn western scientific knowledge, foster a scientific spirit and absorb reasonable ingredients of western traditional thinking ways; westerners should be aware of Chinese traditional thinking ways, inherit and carry the outstanding heritages of traditional thinking and learn the essence of Chinese traditional thinking ways. 


\section{Acknowledgement}

This paper is funded by Soft Science Project of Henan Science and Technology Agency, the Project Number is 162400410538.

\section{References}

[1] Bavis, L. Doing Culture: Cross-culture Communication in Action [M].

Beijing: Foreign Language Teaching and Research Press, 2001.

[2] Dodd, L. Doing Dynamics of Intercultural Communication [M]. New York: McGraw Hill Higher Education, 1998.

[3] Gu Jiazu, Lu sheng. Language and Culture (second edition)[M]. Shang Hai: Shang Hai Foreign Language Education Press, 2002.

[4]Kaplan, Robert B. "Culture Thought Patterns in Intercultural Education" [J]. Language Learning, 1996(01): 15.

[5] Samovar, L. \&Porter, R. Intercultural Communication: A Reader [M].

New York: Wadsworth Publishing Company, 1997.

[6]Wu Chun. The Chinese Thinking Form[M]. Shang Hai: Shang Hai

People's Press.

[7] Zheng Hongfeng . Tang Poems, Song Ci and Yuan Qu [M]. Jilin: Jilin press, 2015: 25.

[8] Zhuangzi. Zhuang-zi [M]. Beijing: China's overseas Chinese press, 2014: 35. 